\title{
The Influence of Traditional Games on Social Behavior of Young Millennials
}

\author{
Hana Astria Nur*, Amung Ma'mun \\ Sport Education School of Postgraduate Studies \\ Universitas Pendidikan Indonesia \\ Bandung, Indonesia \\ *nurhanaastria@gmail.com
}

\author{
Mustika Fitri \\ Faculty of Sport and Health Education \\ Universitas Pendidikan Indonesia \\ Bandung, Indonesia \\ mustikafitri@upi.edu
}

\begin{abstract}
The study aims to examine the influence of traditional games programs (integrating social behavior) to develop social behavior. Experimental method pretest-posttest control group design with more than one experimental group was used in the study. The design is used by involving more than one experimental group. In this study, the experimental group I received the treatment of traditional sports game activities integrated with social behavior, the experimental group II received the treatment of traditional sports game activities, while the control group was given academic extracurricular learning activities. The result indicated that traditional games programs with intentionally structured with integrating processes there were significantly influenced to develop social behavior. Therefore, physical education (PE) teachers can use intentionally structured programs to develop affective aspects through sport activities.
\end{abstract}

\section{Keywords: integrating, social behavior, traditional games}

\section{INTRODUCTION}

Social behavior as one aspect of character education is often discussed, especially in education. In its development, social behavior is often associated with the role of sport which is one of the factors that shape one's character. Research states that sports among adolescents is the main key in the context of character development for various reasons, including the advantages that automatically exist in sports, namely in building social relationships with peers and its potential to support character development [1]. The assumption that sport builds character is still held, at least privately, by many people [2]. Social behavior in this study seeks to develop a number of components that refer to research conducted by Merrel [3], including peer relationships, self-management and the student's academic behavior in school in the community. In essence, a teenager will spend a lot of time in school with teachers and peers. Although it is not uncommon for some adolescents to feel alienated at school, or feel isolated, it is a concern if negative behavior becomes common or is considered a normal behavior. Because it is inevitable that a friendship, especially peers, will definitely engage in mutual mocking or other antisocial behavior, especially in larger schools and with less monitoring. Self-management in this study refers to abilities and skills that can effectively direct their own activities towards achieving goals, setting goals, making decisions, self-evaluation, self-intervention, self-development.
Besides that, academic behavior such as the activity of completing homework (homework), how to behave with teachers and peers, also participate in class and school rules [4$6]$.

This research was conducted towards adolescence, bearing in mind that adolescence is a transition period between childhood and adulthood. In line with research that reveals that adolescence is a transition phase in the direction of adolescents developing into independent adult individuals, where during that phase there are various obstacles that affect their social behavior. In their teens too, they tend to feel depressed and anxious about the changes that occur in social relationships. They also tend to have a more intense relationship with their peers compared to their parents, so there are also more problems with their peers [7-9]. Adolescence are required to have good social behavior. Since having a good behavior, especially social behavior in youth, becomes a basis of optimal human development thru life in social life [10]. The development of behavior itself involves the achievement of feelings, thoughts, and skills needed to act sustainably in treating oneself and others in a good and mutually beneficial manner [11]. Social behavior in this study is the attitude, language, and behavioral responses shown by an individual to other individuals in communicating activities. In the research revealed that social behavior also plays a very important role as the most crucial part in the process of adolescent socialization, as well as being able to predict the social behavior of an individual based on his age level [12]. Based on this research, it can be seen that deviant social behavior is very negative both for themselves, for the school environment, and for other students. Behavior itself consists of qualities that are relevant to efforts to behave ethically (behave properly) in one's relationships with individuals and other communities where the development of these behaviors is the main key in promoting student success [13]. A good character is also not a behavior that is carried from birth, but a behavior that must be learned, both in the home and school environment [14].

In a sport activity there are various types of sports, including games. Games are the most effective learning process which is a real means of education and provides knowledge gained during the preschool period and subsequent school years from one generation to another and supports the development of both physical, cognitive, linguistic and social- 
emotional aspects [15]. But nowadays children do not have enough time to play, both indoor and outdoor as well as playing traditional games especially if they do not know and tend to forget how to play some of these games [16]. Particularly what happened in Indonesia, children and adolescents began to abandon traditional games for four major reasons. First, knowledge or information about traditional games is still lacking. Second, lack of playing areas/ playgrounds so children are unable to play freely. Third, it is difficult to make a playing group in urban areas. The latter is the existence of "game" technology that is developing rapidly, especially in the online gaming sector [17]. This is also in line with research conducted by Khulafa [18] which states that with the rise of social media and online games in Indonesia bringing the impact of social change that makes them an anti-social generation. The anti-social attitude if left unmonitored will cause children to experience moral degradation and increase the attitude of not caring about the environment. Whereas based on research, it shows that by participating in activities such as traditional games, which combine traditional ways and indigenous values, can provide a unique opportunity to enhance youth sports experience, in his research also revealed that traditional games have a historical and cultural foundation which is unique from other European-North American sports (for example, hockey, basketball), which is usually the focus of sports research. Traditional games also have a lot of games that are fun, easy, inexpensive, and simple that can be done with basic movements in sports. Likewise Indonesia is a country with a variety of cultures and local wisdom, which has many traditional games that need to be preserved, having a variety of benefits both in supporting motor skills and cognitive as well as integrating the values of sportsmanship and the character of cooperation [18-20]. Specifically, research on traditional games highlights participants from indigenous youth in Canada about how they were involved in traditional play [19]. But not necessarily with traditional games found in Indonesia, because in a study conducted in Canada, Konya and Spain revealed that traditional games can play a key role in relation to the emotional aspects of physical education. Traditional games can enhance the sports experience of indigenous youth in the aspects of cultural pride, interaction with elders, interaction with nature, and developing basic movements. Traditional games also contribute to the participant's motor, linguistic, cognitive, social-emotional and self-care fields to a certain extent $[15,19,21]$.

\section{RESEARCH METHOD}

\section{A. Research Participants and Procedures}

The sample in this study used a purposive sample technique, the sample of which all members have certain characteristics, namely (1) students who have an age range between 15-18 years, (2) the most active sports and non-sports extracurricular activities in schools, (3) students who are active in extracurricular activities. The subjects in this study were high school students who participated in extracurricular activities at SMA Negeri 1 Cimalaka. The sample selection here is also based on research which states that all participants are teenagers who have played traditional games before through opportunities provided by their school, home, or community [19]. The pretest-posttest control group design research method with more than one experimental group was used in this study, with 50 student samples.

In this study, the experimental group I received the treatment of traditional sports game activities integrated with social behavior, the experimental group II received the treatment of traditional sports game activities, while the control group was given academic extracurricular learning activities. Testing the validity of the instrument first before data collection in the field is done using language validation. Then proceed with the giving of questionnaires for the pretest. In the research process, researchers use a program / scenario that has been prepared previously in the form of a program of traditional sports activities and social behavior. Each meeting was held 2 times per week with different types of traditional games, 45 minutes per time, and continued training for 10 meetings. After the treatment is over, the next step is the implementation of the posttest by giving questionnaire instruments, so that the total meeting held is 12 meetings [19, 22].

\section{B. Research Instruments}

In measuring students' social behavior, researchers use the School Social Behavioral Scales 2 (SSBS 2) measurement tool. SSBS-2 (school social behavior scales 2nd editions) has been tested for validity with the participation of 2,280 students based on age, gender, school environment, community and geographical area, race and ethnicity, socio-economic status, and educational status [23]. The validity of the five-factor structure for students was tested using Confirmatory Factor Analysis with a range of values of 0.76-79 for scale A (social competence) and 0.86-0.89 for scale B (antisocial behavior). Then SSBS-2 (school social behavior scales 2nd editions) was tested again for language validity through theoretical validity and face validity by the Indonesian Language University Education Center \& Indonesian Achievement Learning Center with a conformity value of 0.90 showing very valid criteria and can be used without revision [24]. SSBS-2 (school social behavior scales 2 nd edition) has high reliability through alpha cronbach's test and spearman-brown split half by producing coefficients ranging from 0.96 to 0.98 for a total score of the two main scales and 0.91 to 0,97 for six subscales in all normative samples. Estimated reliability of internal consistency is considered high considering that most of the criteria used to evaluate the internal consistency reliability are total scores and subscale scores of the behavioral assessment scale [25, 26]. SSBS-2 (school social behavior scales 2nd edition) has high reliability through alpha cronbach's test and spearman-brown split half by producing coefficients ranging from 0.96 to 0.98 for a total score of the two main scales and 0.91 to 0,97 for six subscales in all normative samples. Estimated reliability of internal consistency is considered high considering that most of the criteria used to evaluate the internal consistency reliability are total scores and subscale scores of the behavioral assessment scale $[25,26]$. Therefore, the scale and subscale of SSBS-2 can be used to assist in important decisions and treatment choices. Therefore, the scale and subscale of SSBS-2 can be used to assist in important decisions and treatment choices. 
In processing and analyzing data, researchers use ANOVA data analysis, data processing is used referring to research conducted by Pan [27] with acceptance criteria $\alpha=0.05$. Data processing using ANOVA was done because the data in this study were normally distributed and had homogeneous data variance, which had previously been processed using the Kolmogorov-Smirnof test for normality test and Levine test for data homogeneity test. Data processing in this study was assisted with SPSS v.23 for windows software.

\section{RESULT}

On the A scale pretest (social competency) the experimental group I traditional game (gobak sodor, integrated social behavior) obtained an average value $(\pi=$ $118.41)$ with standard deviation $(\sigma=11.09)$ and increased at the posttest with the average value $(\pi=137.71)$ with a range of scores of 19.3 and the standard deviation $(\sigma=10.05)$ with a range of scores of 1.04. In the experimental group pretest II the traditional game (gobak sodor) obtained an average value $(\pi=$ $124.82)$ with a standard deviation $(\sigma=7.59)$ and experienced an increase at the posttest with an average value $(\pi=131.2)$ with a range of scores of 6.38 and standard deviation $(\sigma=$ 10.49 ) with a range of scores of 2.9. In the control group pretest (academic extracurricular learning activities) an average value $(\pi=132.50)$ with standard deviation $(\sigma=9.74)$ and decreased at the posttest with an average value $(\pi=124.56)$ with a range of scores 12.32 and a standard deviation $(\sigma=$ 11.63) with a range of scores 1.89 .

In the pretest scale $\mathrm{B}$ (antisocial behavior) the experimental group I traditional game (gobak sodor, integrated social behavior) obtained an average value $(\pi=78.24)$ with standard deviation $(\sigma=13.79)$ and decreased at the posttest with the average value $(\pi=49.24)$ with a range of scores of 29 and the standard deviation $(\sigma=10.72)$ with a range of scores of 3.07. In the experimental group pretest II the traditional game (gobak sodor) obtained an average value $(\pi=73.24)$ with standard deviation $(\sigma=15.82)$ and decreased at the posttest with an average value $(\pi=54.06)$ with a range of scores of 19 and a standard deviation $(\sigma=12.80)$ with a score range of 3.02. In the control group pretest (academic extracurricular learning activities), the average value $(\pi=63.88)$ was obtained with standard deviation $(\sigma=18.34)$ and decreased at the posttest with an average value $(\pi=61.81)$ with a range of scores of 2.07 and a standard deviation $(\sigma=19.93)$ with a range of scores of 1.59 .

ANOVA testing was conducted to determine the differences in influence between the three groups studied, the results of which showed sig. A scale social behavior is 0,000 $<0.05$ then $\mathrm{H} 0$ is rejected. This means that there are differences in the development of social behavior through traditional games on a scale of social competence. As well as the value of sig. B scale social behavior is $0,000<0.05$ then $\mathrm{H} 0$ is rejected. This means that there are differences in the development of social behavior through traditional games on the scale of antisocial behavior.

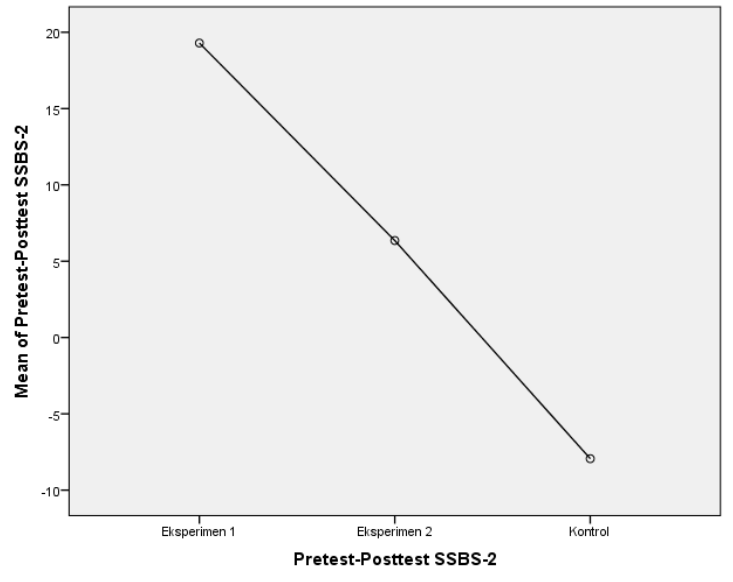

Fig. 1. Means plot of ANOVA SSBS-2 scale a.

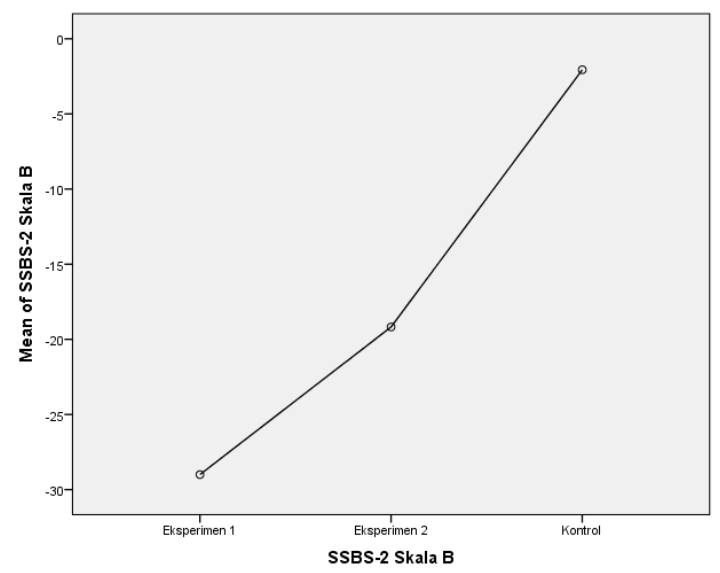

Fig. 2. Means plot of ANOVA SSBS-2 scale b.

\section{DISCUSSION}

There are three components of social behavior given in this study, the peer relations component is the context for developing social skills [4]. Students learn how to interact with others by learning how to maintain good relationships. Peer relationships enable students to be involved in conflict management, empathy, and build social skills provided when implementing the gobak sodor game. When the activity takes place, researchers provide interventions about what is contained in the peer relations component and is applied when the gobak sodor game takes place. Interventions in the form of what they should do and what behavior should appear when the game takes place. Such as how they can effectively participate in groups (for example in carrying out their respective tasks in the game both as a guarding team or playing team), not being picky about friends in the group, easy to open communication in groups, and how to have good leadership skills in groups.

Self-management component refers to the effectiveness of individual methods, skills, and strategies towards achieving and setting goals, planning, tasks, evaluating and selfdevelopment is provided in the traditional game of engklek, 
when the activity takes place students are given an intervention on how to work together (for example in making the game area) since the game engklek is an individual game even though it is played by a large number of players, how to stay calm even when problems arise (for example when the distance he has to push and the area to step on is too far), and how to follow the rules of the game (for example englek gunung, engklek bintang, jawa, etc.), and their attitude when corrected by the teacher when the activity takes place [5].

Component of academic behavior, behavior that is generally associated with being a "good student," including readiness to study, regularly attending classes, paying attention and participating in class, and spending time outside of school to learn and complete assignments on time is provided in the traditional game boy-boyan, when the activity is taking place students are given an intervention in how to listen and follow the teacher's instruction (for example not to throw he ball on any part of the body), how to ask or clarify the rules (eg how many balls to use), as well as how to ask for help from friends and teachers (for example a student asks someone to guard him so as not to get hit by the ball when preparing tiles that have been previously hit by them as the throwing team) [6].

In its implementation, embedding the three components have succeeded in giving significant results to the development of students' social behavior, especially among millennial adolescents, through traditional games (gobak sodor, engklek and boy-boyan). Why should development of social behavior be carried out is in line with research conducted by Harrell, Mercer, \& Derosier suggesting that the development of school social behavior provides benefits related to social learning and supports individual development related to social, emotional, and cognitive functions during adolescence [12]. Gresham, Watson \& Skinner in his research it is said that students can build and maintain satisfying interpersonal relationships, gain friend acceptance, build and maintain friendships, and end negative interpersonal relationships [14]. School social behavior can support the development of social competence by (1) learning how to interact with people in ways that they can receive and respond positively; (2) helps teach him social skills, and; (3) letting others know that they are individual friends and who develop many positive qualities [28]. The development of school social behavior provides the benefits of various skills and abilities, for example, forming emotional bonds, developing social, emotional, cognitive and moral competencies. These aspects will have high value in the healthy development and empowerment of millennial adolescents to face the future [23].

In this study, the control group which is a group with academic extracurricular activities tends to decrease in the development of social behavior of students among millennial adolescents because in their implementation they are only given pretest and posttest, without any treatment in the form of structured physical activity programs that are deliberately made for the development of social behavior. This is in line with research conducted by Kendellen, Bean \& Forneris that groups that are given an intentionally program have more significant results compared to non-intentionally groups [29, 30].

\section{CONCLUSiOnS}

First, based on the results of research that has been done, the results show that there are significant differences in influence in implementing traditional game programs (gobak sodor, engklek and boy-boyan social integration behavior) on the development of social behavior of students. Second, the results of the study indicate that there are differences in influence between groups that are given traditional game programs (gobak sodor, engklek, and boy-boyan) nonintegration and academic learning activity groups. The group with the integration process has a higher score than the other two groups because in the process there is a program created deliberately for the development of social behavior, especially in adolescence. The program is structured so that every component and every aspect of social behavior can be conveyed and can be applied by students both in the research process and in their daily lives.

From this research, it is certain that the program with the integration process has more maximum results in the development of students' social behavior compared to the program without integration (non-integration). In this study it can also be concluded that a traditional game can still play a good role as a fun learning tool to be carried out in the midst of the times, especially in this era among adolescents who are often known as "millennial teens". Where the traditional game is an activity that does not use technology and excessive costs, but can have a "happy" effect when done, a game that creates laughter in the process. In this millennial teenage era, a traditional game can also be raised its existence, its benefits, and its pleasure through social media that is closely linked to the generation of millennial youth.

\section{REFERENCES}

[1] J.P. Agans, S. Su, and A. Vest, "Peer motivational climate and character development: Testing a practitioner-developed youth sport model," Journal of Adolescence, vol. 62, pp. 108-115, 2018.

[2] D.A. Kleiber and G.G. Roberts, "The Effects of Sport Experience in the Development of Social Character: An Exploratory Investigation," Journal of Sport and Exercise Psychology, vol. 3(2), pp. 114-122, 1981.

[3] K.W. Merrel, "Test Review: School Social Behavior Scales, Second Edition," Journal of Psychoeducational Assessment, vol. 25(1), pp. 8292, 2002.

[4] S.L. Gray, C.L. Culpepper, and D.P. Welsh, "Adolescence," Encyclopedia of Human Behavior, pp. 22-29, 2012.

[5] B.P. Ncama, Self, self-care and self-management concepts : implications for self-management education, (January), 2011.

[6] J. Snipes and L. Tran, "Growth mindset, performance avoidance, and academic behaviors in Clark County School District," Regional Educational Laboratory at West Ed, 2017-226, 2017.

[7] B. Buwalda, M. Geerdink, J. Vidal and J.M. Koolhaa, "Neuroscience and Biobehavioral Reviews Social behavior and social stress in adolescence: A focus on animal models," Neuroscience and Biobehavioral Reviews, vol. 35 (8), pp. 1713-1721, 2011.

[8] A.W. Harrell, Mercer, H. strerett and M.E. Derosier, "Improving the Social-Behavioral Adjustment of Adolescents: The Effectiveness of a Social Skills Group Intervention,” J Child Fam Stud, 378-387, 2009.

[9] K.H. Rubin and K.H. Rubin, "Peer relationships Peer Relationships Kenneth H . Rubin, Robert J . Coplan Xinyin Chen, Julie C . Bowker, Kristina L . McDonald, and Sara Heverly-Fitt Center for Children, Relationships, and Culture Department of Human Development 
Skills," In International Conference of Early Childhood Education (ICECE 2017). Atlantis Press, 2017.

[21] P. Lavega, J.I. Alonso, J. Etxebeste, F. Lagardera and J. March, "Relationship Between Traditional Games and the Intensity of Emotions Experienced by Participants Relationship Between Traditional Games and the Intensity of Emotions Experienced by Participants," Research Quarterly for Exercise and Sport, vol. 85(4), 457-467, 2014.

[22] K. Struyven, F. Dochy and S. Janssens, "Teach as you preach ": the effects of student - centred versus lecture - based teaching on student teachers' approaches to teaching," European Journal of Teacher Education, vol. 33(1), 43-64, 2010.

[23] P.L. Benson, P.C. Scales, S.F. Hamilton and A. Sesma, Positive youth development: Theory, research and applications. Hoboken: Wiley, 2006.

[24] R.B. Kline, Principles and Practice of Structural Equation Modeling (2 editions). New York: Guilford, 2005.

[25] B.A. Bracken, L.K. Keith and K.C. Walker, "Assesment of preschool behavior and social-emotional functioning," Journal of Psychoeducational Assessment, 16, 153-169, 1998.

[26] R.G. Floyd and J.E. Bose, "Behavior rating scales for assesment of emotional disturbance: A critical review of measurement characteristic," Journal of Psychoeducational Assessment, vol. 21, 43-78, 2003.

[27] C.-Y. Pan, "Effects of water exercise swimming program on aquatic skills and social behaviors in children with autism spectrum disorders," Autism, vol. 14(1), 9-28, 2010.

[28] N. Frederickson and J.J. Turner, "Utilizing the classroom peer group to address children's social needs: An evaluation of the circle of friends intervention approach," The Journal of Special Education, vol. 36, 234 245, 2003.

[29] C. Bean and T. Forneris, "Examining the importance of intentionally structuring the youth sport context to facilitate positive youth development," Journal of Applied Sport Psychology, vol. 28(4), 410425, 2016.

[30] K. Kendellen, M. Camiré, C.N. Bean, T. Forneris and J. Thompson, "Integrating life skills into Golf Canada's youth programs: Insights into a successful research to practice partnership," Journal of Sport Psychology in Action, vol. 8(1), 34-46, 2017. 